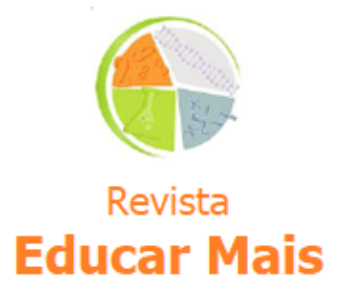

\title{
Força e movimento: concepções alternativas no Ensino Superior
}

\section{Force and movement: alternative conceptions in Higher Sducation}

Miguel Faccio루 ${ }^{1}$ Luiz Marcelo Darroz ${ }^{1}$; Cleci Teresinha Werner da Rosa ${ }^{1}$; Wilson Leandro Krummenauer ${ }^{2}$

\section{RESUMO}

Quando se trata da disciplina de Física, são evidentes as dificuldades dos estudantes (Pérez, Rosa \& Darroz, 2012), que, geralmente, apresentam conceitos construídos por experiências cotidianas em desacordo com a comunidade acadêmica (Carvalho, Vannuchi, Barros, Gonçalves \& Rey, 2007). Diante disso, o presente trabalho expõe os resultados de uma investigação, de natureza qualitativa, que visou identificar se estudantes de Engenharia apresentam falhas conceituais relacionadas ao tópico força e movimento. Para a coleta de dados, utilizou-se um instrumento elaborado e validado por Silveira, Moreira e Axt (1989), e a interpretação dos resultados se deu mediante análises estatísticas. Os resultados demonstram que os participantes apresentam concepções alternativas na interpretação de situações que inter-relacionam força e movimento e força resultante e aceleração.

Palavras-chave: Concepções alternativas; Acadêmicos de Engenharia; Força e movimento.

\begin{abstract}
Abstract: The subject of Physics evidences the difficulties of students (Pérez, Rosa \& Darroz, 2012), who usually present concepts built by everyday experiences that disagree with the academic community (Carvalho, Vannuchi, Barros, Gonçalves \& Rey, 2007). Therefore, the present study exposes the results of a qualitative investigation that aimed to identify whether engineering students present conceptual flaws related to force and movement. The data was collected with an instrument created and validated by Silveira, Moreira, and Axt (1986), and the results were interpreted with statistical analyses. The results show that the participants present alternative conceptions when interpreting situations that interrelate force and movement and resultant force and acceleration.
\end{abstract}

Keywords: Alternative conceptions. Engineering students. Force and movement.

\section{INTRODUÇÃO}

O processo de ensino sempre necessitou de formas inovadoras e de metodologias voltadas a auxiliar os estudantes na compreensão significativa dos conceitos abordados em sala de aula, buscando fazêlos estabelecer interações entre o novo conceito e o já presente na sua estrutura cognitiva (Ausubel, Novak \& Hanesian, 1978). Nessa direção, diversos estudos têm demonstrado a importância de compreender as principais dificuldades por eles enfrentadas, na perspectiva de fornecer aos

\footnotetext{
${ }^{1}$ UPF - Universidade de Passo Fundo, Passo Fundo/RS - Brasil.

${ }^{2}$ Ftec - Faculdade de Tecnologia, Novo Hamburgo/RS - Brasil.
} 
educadores ferramentas pedagógicas capazes de reorganizar os conhecimentos espontâneos dos estudantes, a fim de que eles cheguem às concepções que atendam ao meio científico (Bachelard, 2000).

Uma das barreiras enfrentadas por muitos estudantes na sua trajetória escolar diz respeito a concepções imprecisas de conceitos científicos físicos originados no decorrer de sua experiência no mundo vivencial e que nem sempre estão de acordo com o conhecimento acadêmico (Viennot, 1979). Nessa direção, Silveira, Moreira e Axt (1992) salientam que cada estudante, ao longo de suas atividades cotidianas, interpreta o mundo físico de maneiras diferentes, muitas vezes com uma leitura equivocada do fenômeno, a qual não está de acordo com o meio acadêmico. Essas interpretações, que são conhecimentos pessoais, resistentes a qualquer tipo de mudança e que podem acompanhar os estudantes mesmo na sua caminhada acadêmica, são denominadas de "concepções alternativas" (CA) (Viennot, 1979).

A literatura especializada demonstra que diversos estudos relacionados às CA têm sido desenvolvidos nas últimas décadas. Como exemplo, citam-se os trabalhos de Doran (1972) e Viennot (1979), realizados na década de 1970, e de Watts e Zylbersztajn (1981), Driver, Guesne e Tiberghien, (1985) e Gil-Pérez (1986), datados dos anos 1980, que buscaram identificar quais os conceitos espontâneos internalizados nos estudantes e como eles influenciam no processo de ensinar e aprender.

Na área da Física, estima-se que o pioneiro a pesquisar sobre as CA foi Viennot, em 1979. Em sua pesquisa, o autor revelou que estudantes universitários apresentam noções intuitivas sobre força e movimento. Pouco tempo mais tarde, em 1982, Villani, Pacca, Kishinami e Hosoume, e constataram que acadêmicos apresentam diversas relações espontâneas entre força e velocidade. Clement, por sua vez, também no ano de 1982, desenvolveu uma investigação junto a estudantes americanos de Engenharia, analisando o movimento de uma moeda arremessada para o alto, e concluiu que esses sujeitos assumem ideias equivocadas sobre o conteúdo em foco.

Pouco mais tarde, Silveira et al. (1992) apresentaram um levantamento sobre as concepções alternativas presentes em alunos de Engenharias. A proposta foi aplicada a um grupo de alunos de Engenharia de uma universidade do Rio Grande do Sul. Os resultados evidenciaram que, mesmo após terem cursado a disciplina de Mecânica Clássica, os participantes cometeram erros conceituais, indicando certa resistência ao aprendizado científico.

Frente aos dados encontrados por Silveira et al. (1992), e considerando que, no decorrer dos anos, diversos pesquisadores se dedicaram ao estudo das CA (Silveira et al., 1992; Cunha \& Caldas, 2001; Harres, 2002; Pérez, Rosa \& Darroz, 2012), surge a seguinte indagação que constitui o problema de pesquisa deste estudo: após mais de duas décadas da aplicação do teste elaborado por Silveira et al. (1992), as concepções alternativas referentes ao tópico força e movimento ainda permanecem presentes em estudantes de Engenharia?

Diante desse contexto, o presente trabalho visa divulgar os resultados de uma investigação quantitativa realizada junto a um grupo de acadêmicos dos cursos de Engenharia de uma universidade do interior do Rio Grande do Sul, na qual se buscou identificar se esses sujeitos apresentam concepções alternativas em relação aos tópicos força e movimento e força resultante e aceleração. 
Para alcançar o objetivo proposto, este texto estrutura-se da seguinte forma: na sequência, discutemse as concepções científicas acerca do tema; a seguir, apresenta-se a metodologia utilizada no estudo; no quarto item, são apresentados e discutidos os resultados; e, na última sessão, tecem-se as considerações finais da investigação.

\section{CONCEPÇÕES ALTERNATIVAS E PROCESSO DE ENSINO}

As pesquisas em Ensino de Física trazem contribuições grandiosas para a educação, tendo como objetivo melhorar cada vez mais a compreensão dos estudos relacionados à Física e irromper a grande redoma negativa criada em torno da disciplina. Em busca de novas metodologias voltadas a melhorar a compreensão no ato de aprender, inúmeras formas de aprendizagem são desenvolvidas, porém, em um ambiente escolar, existem diversas maneiras de aprender, isto é, cada aluno dispõe de sua própria forma de aprendizado e de compreensão dos conceitos (Paviani \& Paviani, 2014).

Na direção de encontrar formas de compreender como se aprende, inúmeras pesquisas vêm proporcionando discussões sobre os conceitos espontâneos dos estudantes. Carvalho, Vannuchi, Barros, Gonçalves e Rey (2007), em suas investigações, têm salientado que esses conhecimentos estão relacionados a acontecimentos cotidianos que os alunos levam para a sala de aula. Nesse sentido, os autores salientam que

[...] é a partir dos conhecimentos que os alunos trazem para a sala de aula que eles entendem o que se apresenta em classe [...] os alunos trazem para a sala de aula conhecimentos já construídos, com os quais ouvem e interpretam o que falamos. Esses conhecimentos foram construídos durante sua vida através de interações com o meio físico e social e na procura de explicações do mundo. [...] a criança constrói de maneira espontânea conceitos sobre o mundo que a cerca [...] esses conceitos em muitos casos chegam naturalmente a um estágio pré-científico com uma certa coerência interna (Carvalho et al., 2007, p. 14).

Esses preconceitos são conhecidos no meio acadêmico como concepções alternativas, as quais estão ligadas à estrutura cognitiva do estudante e são corroboradas por experiências sensoriais presentes no dia a dia (Pozo, 1996). De acordo com Driver, Asoko, Leach, Mortimer e Scott (1999), esse tipo de conhecimento transita entre as concepções espontâneas e científicas, uma vez que são oriundas de explicações dadas a fenômenos observados e que não são cientificamente corretas. Nas palavras dos autores,

As formas "de senso comum" de explicar os fenômenos [...] representam o conhecimento do mundo descrito dentro da cultura do dia-a-dia. Elas diferem do conhecimento da comunidade científica de várias maneiras. Obviamente, o senso comum e a ciência diferem nas entidades ontológicas que contêm. As entidades tidas como reais dentro do discurso do dia-a-dia diferem das entidades da comunidade científica (Driver et al., 1999, p. 34).

Nesse cenário, e de maneira mais objetiva, Driver et al. (1999, p. 34), explanam que "[...] os jovens possuem vários esquemas de conhecimento utilizados para interpretar os fenômenos com que se deparam no seu dia-a-dia. Esses esquemas são fortemente apoiados pela experiência pessoal e pela socialização em uma visão de senso comum".

Mortimer (1996), por sua vez, salienta que esses conhecimentos são pessoais, fortemente influenciados pelo contexto do problema e bastante estáveis e resistentes à mudança, de modo que é possível encontrá-los mesmo entre estudantes universitários (Viennot, 1979 apud Mortimer, 1996, 
p. 205-221). Isso significa que, ao aprofundar a discussão sobre o tema, é possível visualizar a lacuna criada entre o conhecimento científico e a estrutura de conhecimento presente nos indivíduos. $A$ relação espontânea que o aluno traz, muitas vezes, torna-o resistente a um novo conceito, causando dificuldades para que um novo aprendizado se consagre como significativo (Mortimer, 1996).

Na concepção de Driver (1986), mesmo que sejam expostos a ideias que atendem ao viés científico, os alunos podem não reorganizar sua preconcepção do fenômeno e, consequentemente, interpretálas de maneira intuitiva. Ainda, os autores salientam a necessidade de que as crianças pratiquem ciência, para que criem suas próprias insatisfações conceituais, despertando a necessidade do saber científico em suas compreensões.

Para Pérez, Rosa e Darroz (2012), as interpretações intuitivas acompanham iniciantes no universo acadêmico, apresentando algumas falhas consideráveis, quando se trata da disciplina de Física. Segundo os autores, os indivíduos apresentam-se com lacunas preenchidas de conhecimentos preestabelecidos pela sua experiência cotidiana. Tal raciocínio leva-os a desenvolver atalhos mentais para interpretar situações que envolvem fenômenos físicos, como, por exemplo, a ideia de que, para um objeto ter movimento, é necessário que uma força aja sobre ele (Driver et al., 1999).

No entendimento de Mors (1997), essa forma de raciocínio opinativo se caracteriza como ingênua e pode ser denominada "Física de senso comum", ou a própria "Física Aristotélica", a qual se atém a pensamentos superficiais e errôneos que prejudicam o aluno no desenvolvimento do conhecimento de respaldo científico. De acordo com Villani et al. (1982, p. 125-150),

[...] na realidade há um confronto entre a Física ensinada (oficial) e a espontânea e sem dúvida o objetivo do ensino é a aprendizagem da oficial; este confronto muitas vezes se realiza de forma pouco harmoniosa, e seu resultado não é uma visão conceitual coerente e rica, mas a superposição e justaposição de conceitos de diferentes origens e alcance, que prejudicam qualquer pretensão de aprofundamento teórico do aluno.

Na visão de Villani et al. (1982), o aprofundamento científico pode ser dificultado quando um conflito entre perspectivas não se der de maneira mediada. Nesse caso, a sobrecarga de informações leva o aluno a se ater a um emaranhado de conceitos, causando uma inconsistência na compressão newtoniana do fenômeno, o qual pode ter sido novamente interpretado de maneira intuitiva.

A fim de reverter o quadro negativo ocasionado por essa falha conceitual, Bachelard (1996) descreveu que é a partir da mudança conceitual que se constrói um indivíduo com pensamento científico, capaz de transitar entre os conceitos sem equívocos. Nas palavras do filósofo, "[...] o adolescente entra na aula de física com conhecimentos empíricos já constituídos: não se trata, portanto, de adquirir uma cultura experimental, mas sim de mudar de cultura experimental, de derrubar os obstáculos já sedimentados pela vida cotidiana" (Bachelard, 1996, p. 23).

A mudança conceitual, chamada de "ruptura" por Bachelard (1996), ocorre quando o estudante tem em seu pensamento o conceito científico esclarecido. Essa ruptura entre conhecimento pré-científico e científico se dá quando o indivíduo entende que o conhecimento pré-científico está carregado de realismos imediatos que determinam falsos pontos de partida e concepções errôneas (Ramos \& Scarinci, 2013). 
O professor deve buscar organizar as ideias do estudante, a fim de reeducar o pensamento, favorecendo a inquietude dos conhecimentos. Nesse sentido, Mortimer (1996) aponta que, quando colocadas em conflito, as ideias alternativas podem se transformar em ideias científicas. A situação conflitiva tem, portanto, papel crucial para uma ruptura do senso comum. Para isso, o professor precisa mediar situações de aprendizagem manipuladas, onde são colocados em teste os conhecimentos alternativos dos alunos, com o objetivo de explicitar a deficiência conceitual de tal concepção sobre o fenômeno envolvido, despertando, assim, a internalização do novo aprendizado, dessa vez científico, mesmo que este contraponha as ideias anteriores (El-Hani \& Bizzo, 2002).

No mesmo contexto, Bourdieu, Chamboredon e Passeron (1999, p. 17) ressaltam que

Semelhante tarefa, propriamente epistemológica, consiste em descobrir no decorrer da própria atividade científica, incessantemente confrontada com o erro, as condições nas quais é possível tirar o verdadeiro do falso, passando de um conhecimento menos verdadeiro a um conhecimento mais verdadeiro, ou melhor, como afirma Bachelard, "próximo, isto é, retificado".

Pode-se dizer que o conhecimento científico constitui uma linguagem universal, pela qual são explicadas as situações presenciadas no dia a dia. A construção de tal conhecimento tem seu início nas concepções espontâneas, em que cada indivíduo, através de ferramentas proporcionadas pelo meio científico, busca a transposição, a internalização do novo saber, não abandonando o antigo, porém reestruturando-o. Ou seja, "a formação do espírito científico é não apenas reforma do conhecimento vulgar, mas ainda uma conversão dos interesses" (Bachelard, 1997, p. 32). Ainda, na expressão do autor: "[...] Para um espírito científico, todo o conhecimento é uma resposta a uma questão. Se não houver uma questão, não pode haver conhecimento científico. Nada é natural. Nada é dado. Tudo é construído" (Bachelard, 2001, p. 166).

A necessidade do saber científico se intensifica à medida que o tempo passa. As pesquisas apontam a atual situação do conhecimento, porém, diante de todas as filosofias, propostas e métodos para desenvolver a cientificidade na população, as concepções alternativas ainda se fazem presentes, dificultando a aprendizagem crítica.

A construção do conhecimento científico tem uma importância fundamental na estrutura dos indivíduos. As intepretações errôneas sustentam basicamente os estudantes que buscam substituílas, a fim de desenvolver sempre o saber científico. Nesse sentido, a investigação aqui descrita visa identificar as concepções de acadêmicos de Engenharia sobre força e movimento, a fim de auxiliar os docentes dessas áreas na direção do desenvolvimento do conhecimento cientificamente correto.

\section{A PESQUISA}

A fim de identificar as concepções alternativas em estudantes universitários, Silveira, Moreira e Axt (1989) elaboraram e validaram um teste composto de 19 questões que abordam os conceitos de mecânica. Segundo os autores, algumas questões foram retiradas da literatura, especialmente dos trabalhos de Watts e Zylbersztajn (1981) e Sebastiá (1984), e outras foram por eles elaboradas buscando maior aprofundamento no tema.

O questionário consiste em um teste com questões fechadas e de múltipla escolha (ANEXO A), divididas em dois grupos, denominados "subteste I" e "subteste II", os quais visam identificar, mediante escores numéricos, as concepções presentes nos estudantes investigados. Um escore 
elevado no subteste I exibe uma concepção newtoniana, e um escore próximo a zero revela uma concepção alternativa na interpretação de situações que relacionam força e movimento. Da mesma forma, no subteste II, um escore elevado determina uma perspectiva newtoniana da relação entre força resultante e aceleração, e um escore próximo a zero, uma concepção não newtoniana.

Esse teste foi aplicado por Silveira et al. (1992) junto a um grupo de 257 acadêmicos do curso de Engenharia Mecânica da Universidade Federal do Rio Grande do Sul, no decorrer do desenvolvimento da disciplina de Física I. Os dados foram analisados quantitativamente, seguindo os pressupostos para análise fatorial, discriminante e de estudos correlacionais, de Nunnally (1967), de Wherry (1984) e de Lord e Novick (1968). Ao final das análises, os pesquisadores concluíram que, mesmo após o curso de Introdução à Mecânica Clássica, que tratou dos conceitos presentes na investigação, parte dos estudantes ainda demonstrou erros conceituais. Nas palavras dos autores, "[...] o estudante pode até obter um escore razoável no teste e, ainda assim, ter uma concepção alternativa" (Silveira et al., 1992, p. 191).

Nessa perspectiva, após mais de 25 anos da aplicação do teste por Silveira et al. (1992), esta investigação tem o intuito de analisar o modo pelo qual os conceitos relacionados com força e movimento e com força resultante e aceleração são compreendidos por estudantes universitários, ou seja, verificar se esses acadêmicos interpretam situações físicas de maneira newtoniana. Dessa forma, a pesquisa caracteriza-se como quantitativa, metodologia que se mostrou pertinente nesse contexto, visto que os dados apresentados descrevem o cenário atual das CA.

Sobre isso, Fonseca (2002, p. 20) afirma que

Como as amostras geralmente são grandes e consideradas representativas da população, os resultados são tomados como se constituíssem um retrato real de toda a população alvo da pesquisa. A pesquisa quantitativa se centra na objetividade. [...]. A pesquisa quantitativa recorre à linguagem matemática para descrever as causas de um fenômeno, as relações entre variáveis, etc. [...].

A pesquisa foi desenvolvida no segundo semestre de 2018 e teve como instrumento de coleta de dados o questionário elaborado e validado por Silveira et al. (1989), descrito anteriormente. Compôs o rol de participantes da pesquisa um grupo de 67 graduandos do segundo nível dos cursos de Engenharia Civil e de Engenharia Mecânica de uma universidade do Norte do estado do Rio Grande do Sul. Cabe ressaltar que os estudantes selecionados para a participação na pesquisa haviam tido contato prévio com os conceitos referentes a este trabalho na disciplina de Física I, que aborda os conceitos fundamentais de Mecânica Clássica.

A coleta dos dados foi efetuada pelo professor titular da disciplina. Em seguida, as respostas foram tabuladas e analisadas estatisticamente, buscando estabelecer um estudo comparativo entre os resultados deste estudo e os encontrados por Silveira et al. (1992), além de conhecer a atual situação das concepções relativas ao tema.

Para estabelecer os resultados comparativos, foi utilizado o método qui-quadrado, que verifica se os resultados provenientes de duas ou mais amostras têm a mesma proporção (probabilidade de ocorrência) de indivíduos com a mesma característica. Para a análise, foi utilizado o nível de 
significância de 5\% (0,05), em que p-valores inferiores a 0,05 $(p<0,05)$ indicam a existência de diferenças estatisticamente significativas.

Na sequência, efetuou-se uma distribuição de frequência das respostas assertivas e para as demais alternativas. Através dessa distribuição e dos grupos de questões, realizou-se uma análise mais detalhada das respostas, trazendo alguns apontamentos importantes, como os principais equívocos cometidos pelos estudantes na interpretação.

Na seção a seguir, são apresentados os resultados obtidos e uma discussão sobre as interpretações efetuadas.

\section{APRESENTAÇÃO E DISCUSSÃO DOS RESULTADOS}

Como se percebe, com base nos dados obtidos no teste qui-quadrado, dispostos no Quadro 1, os resultados desta investigação evidenciam diferenças estatisticamente significativas em relação aos encontrados por Silveira et al. (1992). Na tentativa de elucidar onde pairam as diferenças, apresentam-se, na sequência, os dados obtidos na análise de distribuição de frequência das respostas.

Quadro 1 - Resultados obtidos no teste qui-quadrado.

\begin{tabular}{|c|c|c|c|}
\hline Questões & $\mathbf{p}$ & Questões & $\mathbf{p}$ \\
\hline $\mathbf{1}$ & $\mathrm{p}<00001$ & $\mathbf{1 1}$ & $\mathrm{p}=0,0025$ \\
\hline $\mathbf{2}$ & $\mathrm{p}<00001$ & $\mathbf{1 2}$ & $\mathrm{p}<00001$ \\
\hline $\mathbf{3}$ & $\mathrm{p}<00001$ & $\mathbf{1 3}$ & $\mathrm{p}<00001$ \\
\hline $\mathbf{4}$ & $\mathrm{p}<00001$ & $\mathbf{1 4}$ & $\mathrm{p}<00001$ \\
\hline $\mathbf{5}$ & $\mathrm{p}<00001$ & $\mathbf{1 5}$ & $\mathrm{p}=0,0005$ \\
\hline $\mathbf{6}$ & $\mathrm{p}<00001$ & $\mathbf{1 6}$ & $\mathrm{p}<00001$ \\
\hline $\mathbf{7}$ & $\mathrm{p}<00001$ & $\mathbf{1 7}$ & $\mathrm{p}<00001$ \\
\hline $\mathbf{8}$ & $\mathrm{p}=00161$ & $\mathbf{1 8}$ & $\mathrm{p}<00001$ \\
\hline $\mathbf{9}$ & $\mathrm{p}<00001$ & $\mathbf{1 9}$ & $\mathrm{p}<00001$ \\
\hline $\mathbf{1 0}$ & $\mathrm{p}<00001$ &
\end{tabular}

Os resultados apresentados a seguir referem-se às questões que fazem parte do subteste I, composto dos conjuntos de questões 1 a 6 e 15 a 19, e buscam verificar se os acadêmicos percebem a interrelação entre força e movimento (Silveira et al., 1992).

As três primeiras questões do instrumento aplicado associam a compreensão da relação entre força e movimento. Para tanto, elas apresentam um lançamento vertical que deve ser analisado em três diferentes pontos na trajetória. Essas questões têm como objetivo identificar se os participantes compreendem que, num movimento sem a influência da resistência, a única força que age sobre o corpo é a força peso.

O Quadro 2 contém a distribuição de frequência de respostas dos participantes da pesquisa nas assertivas das três questões iniciais. Como se percebe, as respostas dadas pelos participantes transitam entre todas as assertivas contidas no teste. 
Quadro 2 - Distribuição de frequência das respostas da investigação de 2018 nas três primeiras questões do teste.

\begin{tabular}{|c|c|c|c|c|c|}
\hline Questão & $\boldsymbol{A}$ & $\boldsymbol{B}$ & $\boldsymbol{C}$ & $\boldsymbol{D}$ & $\boldsymbol{E}$ \\
\hline $\mathbf{1}$ & $17,9 \%$ & $9,0 \%$ & $4,5 \%$ & $61,2 \%$ & $7,5 \%$ \\
\hline $\mathbf{2}$ & $3,0 \%$ & $25,4 \%$ & $7,5 \%$ & $19,4 \%$ & $44,8 \%$ \\
\hline 3 & $49,3 \%$ & $25,4 \%$ & $14,9 \%$ & $3,0 \%$ & $7,5 \%$ \\
\hline
\end{tabular}

Fonte: dados da pesquisa (2018).

Na questão 1, que corresponde ao momento de subida da bola, apenas 4,5\% dos participantes marcaram a alternativa que apresenta a compreensão de que, se o objeto está livre da ação do ar em qualquer ponto da trajetória, a única força que age sobre ele é o seu próprio peso. Os resultados também revelam que a maioria dos participantes desta investigação $(61,2 \%)$ compreende que existe uma força aplicada e maior que o peso da bola no sentido do movimento.

A questão 2 aborda o momento em que a bola atinge o ponto mais alto do lançamento vertical. Os resultados encontrados nesta investigação dão conta de que somente $19,4 \%$ dos estudantes participantes da pesquisa compreendem que o objeto está livre das forças de resistência do ar, ou seja, que a única força que age sobre ele é o seu próprio peso. Para a maior parte deste grupo $(44,8 \%)$, ao atingir a altura máxima do lançamento vertical, o somatório das forças sobre a bola é nulo.

Na questão 3, a compreensão investigada diz respeito à interpretação sobre o momento em que a bola retorna ao solo. 0 índice de participantes que interpretam a situação de forma fisicamente correta é de $49,3 \%$. No entanto, os dados indicam que um grupo $(14,9 \%)$ concebe a presença de uma força na mesma direção e sentido da força peso.

A interpretação dos resultados dessas questões aponta que, ao contrário da maioria dos investigados por Silveira et al. (1992), a maior parte dos sujeitos desta pesquisa interpreta de maneira não newtoniana as forças envolvidas nas situações descritas. Isto é, constata-se que a maioria dos participantes interpreta que o vetor que representa a força está agindo num corpo e está associado ao sentido do movimento desse objeto.

A questão 4 apresenta um plano inclinado onde um corpo é abandonado em repouso, desliza sobre o plano sem força resistiva do ar, com força de atrito constante e com aceleração também constante. De acordo com os resultados encontrados, enquanto $28,4 \%$ dos participantes associam uma aceleração constante a um somatório de forças constante, $61,2 \%$ compreendem que a velocidade é aumentada em virtude do aumento da força aplicada. Esses resultados indicam a existência de concepções equivocadas sobre o fenômeno.

As questões 5 e 6, que tratam de movimento circular, buscam analisar se os participantes identificam corretamente as forças que estão sendo exercidas sobre os corpos envolvidos no movimento. 0 Quadro 3 apresenta os índices de frequência das respostas atribuídas pelos participantes a cada uma das assertivas das questões.

Quadro 3 - Distribuição das respostas obtidas na investigação de 2018 em cada uma das assertivas das questões 5 e 6.

\begin{tabular}{|c|c|c|c|c|c|}
\hline Questão & $\boldsymbol{A}$ & $\boldsymbol{B}$ & $\boldsymbol{C}$ & $\boldsymbol{D}$ & $\boldsymbol{E}$ \\
\hline $\boldsymbol{5}$ & $32,8 \%$ & $11,9 \%$ & $11,9 \%$ & $38,8 \%$ & $4,5 \%$ \\
\hline $\boldsymbol{6}$ & $10,4 \%$ & $7,5 \%$ & $38,8 \%$ & $34,3 \%$ & $9,0 \%$ \\
\hline
\end{tabular}

Fonte: dados da pesquisa (2018). 
Como se percebe no Quadro 3, na questão 5, apenas 4,5\% dos participantes optaram pela alternativa que apresenta a concepção newtoniana, a qual refere que na situação descrita existe apenas a força gravitacional atuando sobre o satélite. Evidencia-se, também, que 38,8\% dos participantes assinalaram a opção que indica a existência de uma segunda força no sentido do movimento e que apresenta resultados semelhantes na questão seguinte.

Na questão 6, apenas 7,5\% dos participantes demonstram compreender a existência de duas forças - centrípeta e peso - agindo sobre a pedra. Para 38,8\% deles, existiria uma terceira força agindo na direção do movimento. Isto é, esse grupo apresenta a concepção não newtoniana de que sempre existe uma força na direção do movimento.

A questão 15 ilustra o arremesso de uma pedra que passa a cair num movimento de queda livre do alto de uma torre. Os participantes analisaram as forças que atuariam sobre a pedra em três pontos distintos da trajetória. Conforme os resultados, 37,3\% dos pesquisados compreendem que, ao deixar de estar em contato com a mão do arremessador, a única força que age sobre a pedra é a força peso. Os resultados da presente investigação reiteram, assim, que $44,8 \%$ dos pesquisados apresentam a concepção da existência de outra força - além do peso - na direção do movimento.

A questão 16 assemelha-se à questão 15 , por exigir dos participantes a interpretação do diagrama das forças que agem horizontalmente no corpo em três pontos distintos da trajetória desenvolvida no movimento com aceleração constante. Para apenas 6,3\% dos participantes, após a bola ser lançada pelo indivíduo, há somente a força de atrito agindo sobre ela. A maioria dos participantes da pesquisa $(64,1 \%)$ compreende que há uma força decrescente no sentido do movimento. Tais dados indicam, mais uma vez, que os participantes concebem a existência de uma força agindo na direção do movimento do corpo.

As questões 17, 18 e 19 abordam o lançamento de uma pequena pedra que descreve uma trajetória oblíqua, onde a força de resistência do ar sobre ela é desprezível. Essas questões buscam identificar, novamente, a concepção dos participantes sobre a inter-relação entre força e movimento. O Quadro 4 sintetiza os índices de respostas em cada uma das alternativas dessas questões.

Quadro 4 - Índices de respostas obtidas na investigação de 2018 em cada uma das alternativas das questões 17,18 e 19.

\begin{tabular}{|c|c|c|c|c|c|}
\hline Questão & $\boldsymbol{A}$ & $\boldsymbol{B}$ & $\boldsymbol{C}$ & $\boldsymbol{D}$ & $\boldsymbol{E}$ \\
\hline $\mathbf{1 7}$ & $46,9 \%$ & $17,2 \%$ & $28,1 \%$ & $0,0 \%$ & $7,8 \%$ \\
\hline $\mathbf{1 8}$ & $3,1 \%$ & $35,9 \%$ & $9,4 \%$ & $43,8 \%$ & $7,8 \%$ \\
\hline $\mathbf{1 9}$ & $4,7 \%$ & $6,3 \%$ & $12,5 \%$ & $67,2 \%$ & $9,4 \%$ \\
\hline
\end{tabular}

Fonte: dados da pesquisa (2018).

De acordo com os resultados da questão 17 , que interpreta as forças presentes no momento de subida do objeto, $49 \%$ dos participantes concebem que, no ponto analisado, apenas a força peso está agindo sobre o corpo. No entanto, para $46,9 \%$ dos participantes, além dessa força, existe outra no sentido do movimento.

Na questão 18, a situação prevê a interpretação dos participantes sobre as forças que agem no corpo no ponto mais alto da trajetória. Os resultados obtidos na alternativa que apresenta uma concepção diferente da newtoniana são muito parecidos com os encontrados na questão anterior. Para $43,8 \%$ dos participantes, no ponto mais alto da trajetória do objeto, existe, além da força peso, uma segunda 
força no sentido do movimento. Ainda, os resultados dessa questão dão conta de que apenas $3,1 \%$ compreendem a inter-relação entre força e movimento de forma newtoniana.

A questão 19 busca identificar a interpretação dos participantes acerca das forças que atuam no objeto na trajetória de descida. Os resultados encontrados indicam que apenas 9,4\% dos participantes escolheram a alternativa que demonstra a concepção newtoniana da situação, onde age apenas a força peso sobre o corpo. Para $67,2 \%$ dos acadêmicos pesquisados, estão presentes a força peso e, também, uma força no sentido do movimento do objeto.

A análise dos resultados obtidos nas questões relativas ao subteste I revela que a maioria dos participantes desta investigação não interpreta de maneira newtoniana as forças envolvidas nas situações propostas. Para a maior parte deles, em todas as situações descritas no teste, há uma força no sentido do movimento. Dessa forma, conclui-se que os pesquisados apresentam concepções alternativas para interpretar a inter-relação entre força e movimento.

A partir deste ponto, apresentam-se e discutem-se os resultados das questões 7 a 14, pertencentes à segunda parte do teste, o subteste II. Essas questões visam evidenciar se os acadêmicos relacionam ou não a força resultante com a aceleração (Silveira et al., 1992).

As questões 7, 8 e 9 fazem referência à situação em que um indivíduo exerce uma força horizontal sobre uma caixa, em uma superfície também horizontal e com atrito, desprezando-se a resistência do ar. O Quadro 5 apresenta os índices de respostas dessas questões.

Quadro 5 - Índices de respostas obtidos na investigação de 2018 em cada uma das alternativas das questões 7,8 e 9.

\begin{tabular}{|c|c|c|c|}
\hline Questão & $\boldsymbol{A}$ & $\boldsymbol{B}$ & $\boldsymbol{C}$ \\
\hline $\boldsymbol{7}$ & $26,9 \%$ & $67,2 \%$ & $6,0 \%$ \\
\hline $\boldsymbol{8}$ & $59,7 \%$ & $11,9 \%$ & $28,4 \%$ \\
\hline $\boldsymbol{9}$ & $29,9 \%$ & $59,7 \%$ & $10,4 \%$ \\
\hline
\end{tabular}

Fonte: dados da pesquisa (2018).

Na questão 7, a situação envolve um indivíduo que exerce uma força de intensidade um pouco maior que a força de atrito, na intenção de verificar se os acadêmicos estabeleceriam corretamente a relação entre força resultante e aceleração. Como se percebe nos dados do Quadro 5, 26,6\% dos participantes assinalaram a alternativa que contém uma resposta newtoniana para a situação, e a maioria $(67,2 \%)$ optou pela alternativa intuitiva de que, se a força resultante é pequena, a velocidade também é pequena.

A questão 8 descreve uma situação em que o indivíduo diminui a intensidade da força aplicada, porém, ela se mantém um pouco maior que a força de atrito. Segundo os resultados, 59,7\% dos participantes da pesquisa compreendem que, ao diminuir a intensidade da força aplicada, a velocidade diminui. Ainda, os resultados indicam que apenas $11,9 \%$ dos investigados apresentam concepções newtonianas sobre a situação.

A questão 9 traz a situação em que a intensidade da força exercida sobre a caixa é igualada à intensidade da força de atrito. Para 10,4\% dos participantes, ao ocorrer essa situação, a caixa passa a se mover com velocidade constante. No entanto, como ilustra o Quadro 5, a maioria dos participantes $(59,7 \%)$ interpreta que, se a força resultante é zero, a caixa deixa de se mover. 
Os resultados encontrados nas questões 7, 8 e 9 permitem concluir que os participantes desta investigação não relacionam força resultante com aceleração de forma newtoniana. Para eles, um objeto só está em movimento se existe uma força resultante agindo sobre ele.

As questões 10 a 14 fazem referência ao sistema de tração (motor e cabo) presente em um elevador que se move verticalmente. O questionamento é acerca da dinâmica assumida pelo elevador após as mudanças de tração fornecidas pelo motor. O Quadro 6 apresenta os índices de respostas em cada uma das alternativas dessas questões.

Quadro 6 - Índices de respostas obtidas na investigação de 2018 em cada uma das alternativas das questões 10 a 14.

\begin{tabular}{|c|c|c|c|}
\hline Questão & $\boldsymbol{A}$ & $\boldsymbol{B}$ & $\boldsymbol{C}$ \\
\hline $\mathbf{1 0}$ & $1,5 \%$ & $13,4 \%$ & $85,1 \%$ \\
\hline $\mathbf{1 1}$ & $6,0 \%$ & $73,1 \%$ & $20,9 \%$ \\
\hline $\mathbf{1 2}$ & $74,6 \%$ & $16,4 \%$ & $9,00 \%$ \\
\hline $\mathbf{1 3}$ & $21,5 \%$ & $53,8 \%$ & $24,6 \%$ \\
\hline $\mathbf{1 4}$ & $22,4 \%$ & $17,9 \%$ & $59,7 \%$ \\
\hline
\end{tabular}

Fonte: dados da pesquisa (2018).

Na questão 10, a situação descrita apresenta o motor exercendo sobre o elevador uma força um pouco mais intensa que o peso, de modo que o elevador saia do repouso e suba. Para $13,4 \%$ dos investigados, o elevador subirá com velocidade que aumenta. A maioria $(85,1 \%)$ assinalou a alternativa que contém a concepção intuitiva de que, se a força resultante é de baixa intensidade, a velocidade é pequena e constante.

A questão 11 aborda a situação em que o elevador está subindo sob a ação de uma força muito mais intensa que a força peso, então a força exercida pelo motor é diminuída, permanecendo ainda um pouco maior que a força peso. Para essa situação, 6,0\% dos participantes compreendem que, mesmo com a intensidade da força resultante diminuída, o elevador continua acelerado. Em relação aos acadêmicos que assinalaram a alternativa correspondente a uma concepção não newtoniana, o índice foi de $73,1 \%$, o que demonstra que a maioria dos participantes relaciona a força resultante com a velocidade do elevador. Para eles, quando a intensidade da força resultante diminui, a velocidade também diminui.

A questão 12 apresenta a situação em que o elevador está subindo pela ação de uma força maior que a sua força peso, e o motor diminui a intensidade força, que se iguala à força peso do próprio elevador. Conforme os resultados, apenas 9,0\% dos investigados optaram pela interpretação newtoniana. Ou seja, a minoria dos participantes interpreta que, nesta situação, o elevador subirá com velocidade constante. Para $74,6 \%$ dos investigados, quando a força resultante é nula, 0 movimento é cessado.

Na questão 13, a situação descreve que o elevador está descendo enquanto o motor exerce uma força menor que o peso, e a intensidade da força aumenta, igualando-se à força peso. De acordo com os resultados, $21,5 \%$ dos acadêmicos investigados assinalaram a alternativa que contém a concepção newtoniana de que o elevador passará a descer em equilíbrio. Novamente, a alternativa que apresenta a ideia de que o movimento é cessado obteve a maior frequência de resposta, tendo em vista que $53,8 \%$ dos participantes a assinalaram. 
Por fim, a questão 14 aborda a situação em que o elevador está descendo, e o motor aumenta a intensidade da força, que se torna muito maior que o peso do elevador. Nessa situação, 17,9\% dos participantes responderam segundo as perspectivas newtonianas, e 59,7\% optaram pela concepção alternativa, indicando que não relacionam o vetor força resultante com aceleração.

Os resultados obtidos nas questões que compõem o subteste II apontam que a maioria dos participantes tem resistência em conceber que a intensidade da força resultante está associada à aceleração do corpo. Percebe-se, ainda, a dificuldade dos investigados em compreender o equilíbrio dinâmico das situações descritas.

\section{CONSIDERAÇÕES FINAIS}

No contexto atual, são inúmeras as dificuldades de aprendizagem, e dentre elas está a intuição dos estudantes ao interpretarem situações do cotidiano que envolvem fenômenos físicos. Nesse sentido, Silveira et al. (1992) salientam que os conhecimentos prévios desses sujeitos, na maioria das vezes, não estão de acordo com o conhecimento científico.

O objetivo desta investigação foi verificar, através de uma análise quantitativa, se acadêmicos de Engenharia apresentam concepções alternativas na inter-relação entre força e movimento e entre força resultante e aceleração. Os resultados alcançados com o teste qui-quadrado para amostras independentes mostraram diferenças estatisticamente significativas entre os achados de Silveira et al. (1992) e os dados obtidos neste trabalho.

No subteste I, os resultados evidenciaram que a maioria dos participantes interpretou de maneira não newtoniana as forças presentes nos casos propostos, como, por exemplo, nas questões 1, 4, 5, 16 , que indicam a dinâmica de lançamento vertical, plano inclinado, movimento circular e lançamento horizontal, respectivamente, onde a frequência de resposta não newtoniana superou o índice de $30 \%$. No subteste II, os resultados indicaram que a maioria dos estudantes não interpretou corretamente as situações, na medida em que suas respostas apresentaram falhas conceituais sobre a relação entre força e aceleração. Constata-se que os acadêmicos não compreenderam o equilíbrio dinâmico nas situações propostas, evidenciando a presença de concepções alternativas.

Diante dos resultados obtidos, pode-se concluir que, embora tenham finalizado o curso introdutório de Física I, os acadêmicos participantes não atingiram a mudança conceitual apontada por Bachelard (1996), isto é, mesmo tendo frequentado disciplina que aborda os conceitos relativos ao tópico força e movimento, os participantes ainda demonstraram equívocos na interpretação do conceito.

Por fim, salienta-se que, apesar das diversas investigações e estudos já realizados em torno da temática, as concepções alternativas ainda são um problema frequente e que acompanha os estudantes até o ensino superior. Nessa perspectiva, para que o cenário seja alterado, acredita-se ser necessário, cada vez mais, desenvolver os conceitos científicos de forma contextualizada, prática e interdisciplinar com base em situações cotidianas, a fim de que os estudantes de nível médio e superior se tornem agentes ativos e participativos do seu processo de ensino, colaborando, assim, para a construção de sua própria explicação científica e promovendo a mudança conceitual (Campos \& Nigro, 2009). 


\section{REFERÊNCIAS}

Ausubel, D.P., Novak, J.D., \& Hanesian, H. (1978). Educational Psychology: a cognitive view. New York: Warbel \& Peck.

Bachelard, G. (1996). A formação do espírito científico: contribuição para uma psicanálise do conhecimento. Rio de Janeiro, $\mathrm{RJ}$ : Contraponto.

Bachelard, G. (1977). O racionalismo aplicado. Rio de Janeiro, RJ: Zahar Editores.

Bachelard, G. (2000). A epistemologia. Lisboa: Edições 70.

Bachelard, G. (2001). O novo espírito científico. Rio de Janeiro, RJ: Tempo Brasileiro.

Bourdieu, P., Chamboredon, J.C., \& Passeron, J.C. (1999). A profissão de Sociólogo: preliminares epistemológicas. 2. ed. Petrópolis, RJ: Vozes.

Campos, M.C.C., \& Nigro, R.G. (2009). Teoria e prática em ciências na escola: o ensino-aprendizagem como investigação. São Paulo, SP: FTD.

Carvalho, A.M.P., Vannuchi, A.I., Barros, M.A., Gonçalves, M.E.R., \& Rey, R.C. (2007). Ciências no ensino fundamental: o conhecimento físico. São Paulo, SP: Scipione.

Clement, J. (1982). Students' preconceptions in introductory mechanics. American Journal of Physics, 50, 66-71.

Cunha, A.L., \& Caldas, H. (2001). Modos de raciocínio baseados na teoria do impetus: um estudo com estudantes e professores do ensino fundamental e médio. Revista Brasileira de Ensino de Física, 23(1), 93-103.

Doran, B.G. (1972). Misconceptions of selected science concepts held by Elementary School students. Journal of Research in Science Teaching, 9(2), 127-137.

Driver, R., Guesne, E., \& Tiberghien, A. (Eds). (1985). Children 's ideas in science. Philadelphia: Milton Keynes - Open University Press.

Driver, R. (1986). Psicologia Cognoscitiva y Esquemas Conceptuales de Los Alumnos. Enseñanza de Las Ciencias, 4(1), 3-15.

Driver, R., Asoko, H., Leach, J., Mortimer, E., \& Scott, P. (1999). Construindo conhecimento científico. Química Nova na Escola, 9, 31-40.

El-Hani, C.N., \& Bizzo, N.M.V. (2002). Formas de construtivismo: mudança conceitual e construtivismo contextual. Revista Ensaio, 4(1), 40-64.

Fonseca, J.J.S. (2002). Metodologia da pesquisa científica. Fortaleza, CE: UEC. (Apostila).

Galili, I., \& Bar, V. (1992). Motion implies force: where to expect vestiges of the misconceptions? International Journal of Science Education, 14(1), 63-81.

Gil-Pérez, D. (1986). La metodología científica y la enseñanza de las ciencias. Unas relaciones controvertidas. Enseñanza de las Ciencias, 4(2), 111-121.

Harres, J.B.S. (2002). Desenvolvimento histórico da dinâmica: referente para a evolução das concepções dos estudantes sobre força e movimento. Revista Brasileira de Pesquisa em Educação em Ciências, 2(2), 89-101. 
Lord, F.M., \& Novick, M.R. (1968). Statistical theories os mental test scores. Addisen- Wesley: London.

Mors, P.M. (1997). Comentários sobre o Curso Introdutório de Física na Universidade. Revista Scientia, 8(1), 85-90.

Mortimer, E.F. (1996). Construtivismo, mudança conceitual e ensino de ciências: para onde vamos? Investigações em Ensino de Ciências, 1(1), 20-39.

Nunnaly, J.C. (1967). Psychometric theory. McGraw-Hill: New York.

Paviani, J., \& Paviani, N.M.S. (2014). Alguns modos de ensinar e aprender. Conjectura: Filosofia $e$ Educação, 19(3), 127-142.

Pérez, C.S., Rosa, C.T.W., \& Darroz, L.M. (2012). Concepções alternativas em mecânica: um estudo de caso dos alunos de cursos de engenharia. Revista de Ensino de Engenharia, 31(2), 79-90.

Ramos, T.A., \& Scarinci, A.L. (2013). Análise de concepções de tempo e espaço entre estudantes do ensino médio, segundo a epistemologia de Gaston Bachelard. Revista Brasileira de Pesquisa em Educação em Ciências, 13(2), 9-25.

Sebastiá, J.M. (1984). Fuerza y movimento: la interpretación de los estudiantes. Enseñanza de las Ciencias, 2(3), 161-169.

Silveira, F.L., Moreira, M.A., \& Axt, R. (1989). Validação de um teste para verificar se o aluno possui concepções científicas sobre corrente elétrica em circuitos simples. Ciência e Cultura, 41(11), 11291133.

Silveira, F.L., Moreira, M.A., \& Axt, R. (1992). Estrutura interna de testes de conhecimento em Física: um exemplo em Mecânica. Enseñanza de las Ciências, 10(2), 187-194.

Viennot, L. (1979). Spontaneous Reasoning in elementary dynamics. European Journal of Science Education, 1(2), 205-221.

Villani, A., Pacca, J.L.A., Kishinami, R.I., \& Hosoume, Y. (1982). Analisando o ensino de Física: contribuições de pesquisas com enfoques diferentes. Revista de Ensino de Física, 4(1), 23-51.

Watts, D., \& Zylbersztajn, A. (1981). A survey of some children's ideas about force. Physics Education, $15,360-365$.

Wherry, R.J. (1984). Contributions to correlational analysis. Academic Press: London. 


\section{ANEXO A}

Este teste* é constituído por dezenove questões de escolha múltipla, com cinco ou três alternativas. Escolha a alternativa que melhor corresponde à resposta e marque na grade em anexo. NÃO FAÇA MARCAS NAS FOLHAS DE QUESTÕES.

As questões 1, 2 e 3 referem-se ao seguinte enunciado:

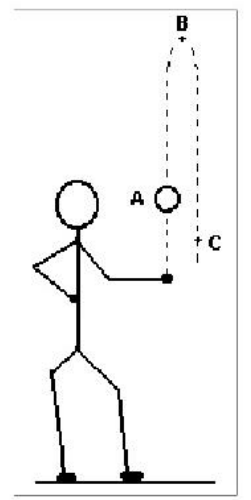

Um menino lança verticalmente para cima uma bola. Os pontos $\mathrm{A}, \mathrm{B}$ e $\mathrm{C}$ identificam algumas posições da bola após o lançamento (B é o ponto mais alto da trajetória). É desprezível a força resistiva do ar na bola.

As setas nos desenhos seguintes simbolizam forças exercidas na bola.

1) No ponto $A$, quando a bola está subindo, qual dos desenhos melhor representa a(s) força(s) exercidas na bola?

A)

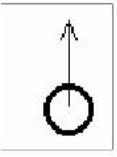

B)

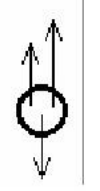

C)

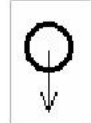

D)<smiles>COc1ccccc1</smiles>

E)

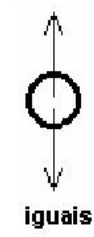

2) No ponto $B$, quando a bola atinge o ponto mais alto da trajetória, qual dos desenhos melhor representa a(s) força(s) exercidas na bola?

A)

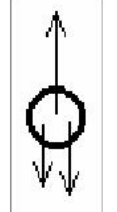

B)

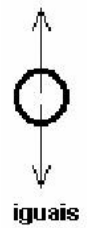

C

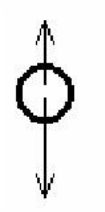

D)

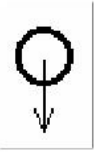

E)

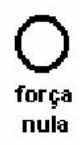

3) No ponto $\mathrm{C}$, quando a bola está descendo, qual dos desenhos melhor representa a(s) força(s) exercidas na bola?

A)

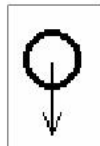

B)

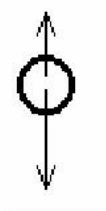

C)

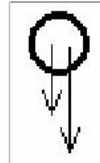

D)

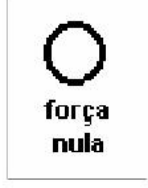

E)

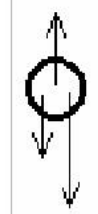

* SILVEIRA, F. L., MOREIRA, M. A. e AXT, R. Estrutura interna de testes de conhecimento em Física: um exemplo em Mecânica. Enseñanza de las Ciencias, Barcelona, 10(2): 187-194, 1992. 
4) A figura se refere a um corpo que foi abandonado em repouso sobre uma rampa (é desprezível a força resistiva do ar no corpo e é constante a força de atrito com a rampa). Ele passa a deslizar com velocidade que cresce uniformemente no tempo. Assim sendo, pode-se afirmar que a força exercida no corpo rampa abaixo:

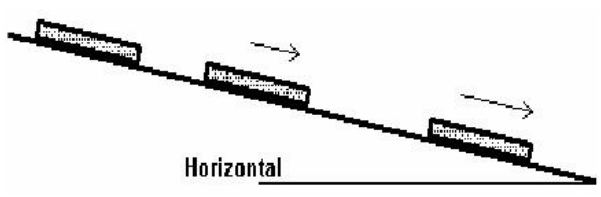

A) é igual à força de atrito.

B) é maior do que a força de atrito e está crescendo.

C) é constante mas maior do que a força de atrito.

5) As figuras se referem a um satélite descrevendo movimento circular uniforme em torno da Terra. As setas simbolizam as forças exercidas sobre o satélite. Qual das figuras melhor representa a(s) força(s) sobre o satélite?
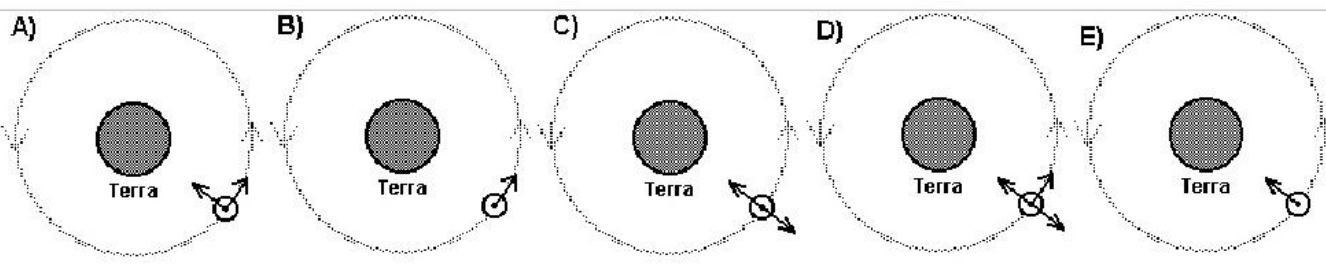

6) As figuras se referem a um menino que faz girar, em uma trajetória circular em um plano vertical, uma pedra presa ao extremo de um fio. Em qual das figuras a(s) força(s) sobre a pedra está(ão) melhor representada(s) pela(s) seta(s)?

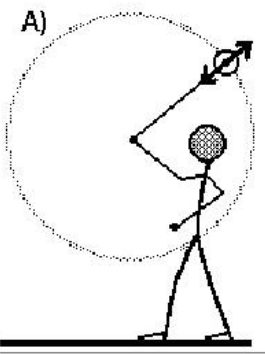

B)

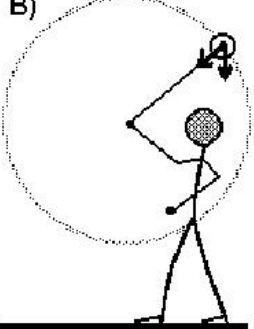

C)

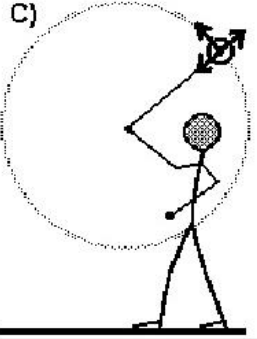

D)

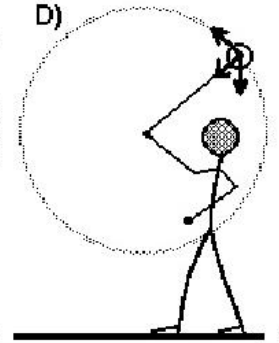

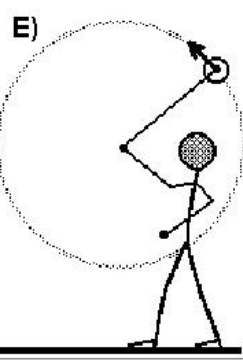

As questões 7, 8 e 9 referem-se ao seguinte enunciado:

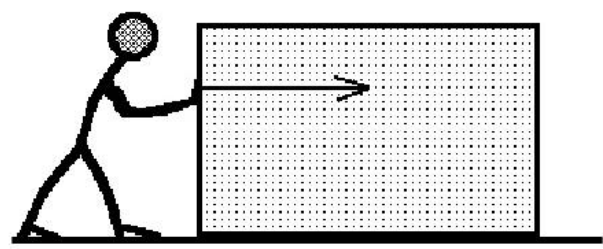

A figura se refere a um indivíduo exercendo uma força horizontal sobre uma caixa. A caixa está sobre uma superfície horizontal com atrito. É desprezível a força de resistência do ar sobre a caixa. 
7) Inicialmente o indivíduo realiza uma força com intensidade um pouco maior do que a força de atrito. Portanto a caixa se movimentará:
A) com velocidade que aumenta.
B) com velocidade pequena e constante.
C) com velocidade grande e constante.

8) A caixa está sendo empurrada por uma força com intensidade muito maior do que a da força de atrito. Então o indivíduo diminui a intensidade da força mas ela continua sendo um pouco mais intensa do que a da força de atrito. Portanto a velocidade da caixa:
A) diminui.
B) aumenta.
C) permanece constante.

9) A caixa está sendo empurrada por uma força com intensidade maior do que a da força de atrito. Então o indivíduo diminui a intensidade da força até que ela se iquale à da força de atrito. Portanto a caixa:
A) continuará se movimentando mas acabará parando.
B) parará em seguida.
C) continuará se movimentando com velocidade constante.

As questões 10 a 14 se referem ao seguinte enunciado:

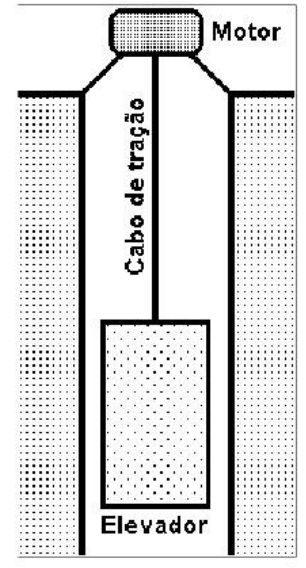

A figura se refere a um elevador e o seu sistema de tração (motor e cabo). Através do cabo o motor exerce uma força sobre o elevador (são desprezíveis as forças de atrito e de resistência do ar sobre o elevador).

10) O elevador está inicialmente parado e então o motor exerce sobre o elevador uma força um pouco mais intensa do que o peso do elevador. Assim sendo, podese afirmar que o elevador subirá:

A) com velocidade grande e constante.

B) com velocidade que aumenta.

C) com velocidade pequena e constante.

11) O elevador está subindo e o motor está exercendo uma força cuja intensidade é muito maior do a do peso do elevador. Então a força que o motor exerce diminui de intensidade mas permanece ainda um pouco maior do que a do peso do elevador. Portanto a velocidade do elevador:
A) aumenta.
B) diminui.
C) não se altera.

12) O elevador está subindo e o motor está exercendo uma força com intensidade maior do que a do peso do elevador. Então a força que o motor exerce diminui de intensidade, se igualando a do peso do elevador. Portanto o elevador:

A) parará em seguida.

B) continuará subindo durante algum tempo mas acabará parando. 
C) continuará subindo com velocidade constante.

13) O elevador está descendo e o motor exerce sobre ele uma força com intensidade menor do que a do peso do elevador. Então a intensidade da força que o motor exerce aumenta e se iguala a do peso do elevador. Portanto o elevador:

A) continurá descendo com velocidade constante.

B) parará em seguida.

C) continuará descendo durante algum tempo mas acabará parando.

14) O elevador está descendo e o motor exerce sobre ele uma força menos intensa do que a do peso do elevador. Então a força que o motor exerce aumenta de intensidade, se tornando muito mais intensa do que o peso do elevador. Portanto o elevador:

A) imediatamente sobe.

B) continua a descer durante algum tempo com velocidade que diminui.

C) imediatamente para e em seguida sobe com grande velocidade.

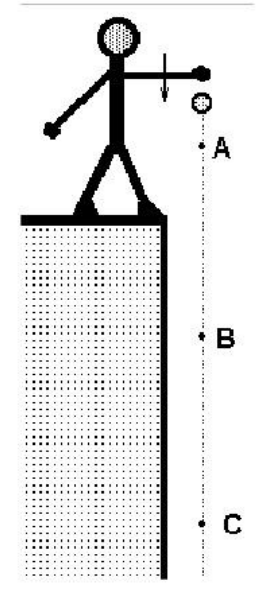

15) A figura se refere a um indivíduo que, do topo de uma torre, arremessa para baixo uma bola. Os pontos $A, B$ e $C$ são pontos da trajetória da bola após o arremesso. É desprezível a força de resistência do ar sobre a bola. As setas nos esquemas seguintes simbolizam as forças exercidas sobre a bola nos pontos A, B e C. Qual dos esquemas seguintes melhor representa $a(s)$ força(s) sobre a bola?
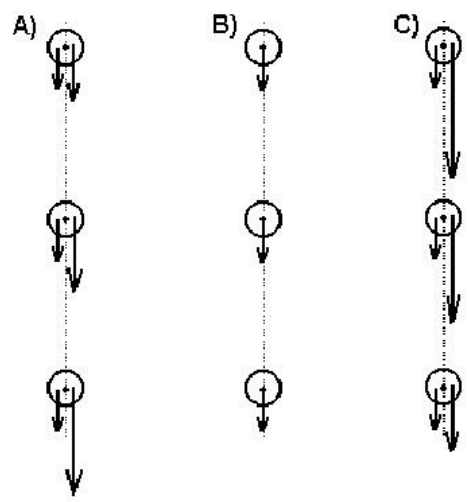
16) A figura se refere a um indivíduo que lança com grande velocidade uma bola sobre uma superfície horizontal com atrito. Os pontos A e B são pontos da trajetória da bola após o lançamento, quando a bola já está rolando; no ponto $\mathrm{C}$ a bola está finalmente em repouso.

As. setas nos desenhos seguintes simbolizam as forças horizontais sobre a bola nos pontos A, B

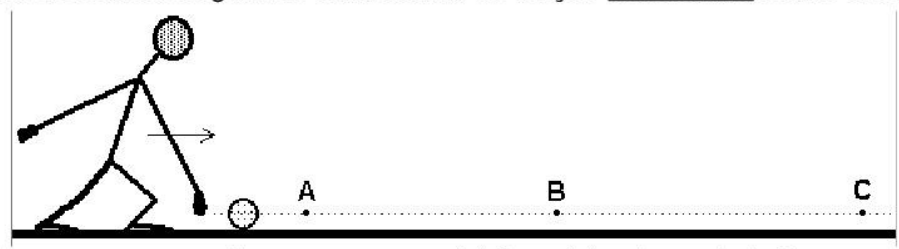

e C. Qual dos esquemas melhor representa a(s) força(s) sobre a bola?

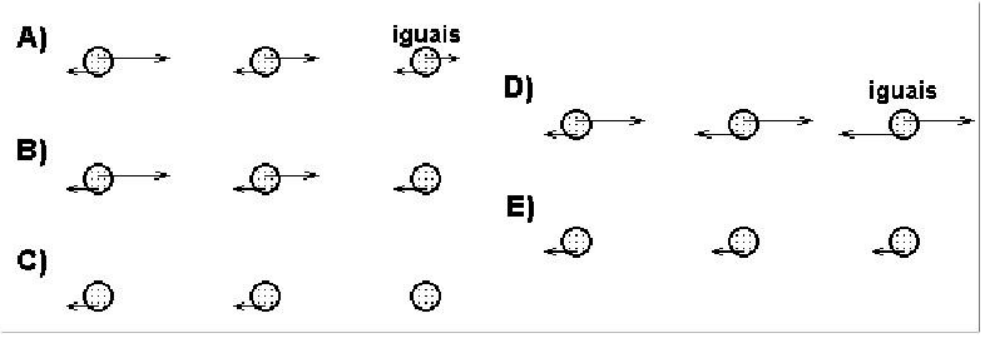

As questões 17, 18 e 19 referem-se ao enunciado abaixo:

Um menino lança uma pequena pedra que descreve uma trajetória como a representada na figura (a força de resistência do ar sobre a pedra é desprezível). O ponto B é o ponto mais alto da trajetória.

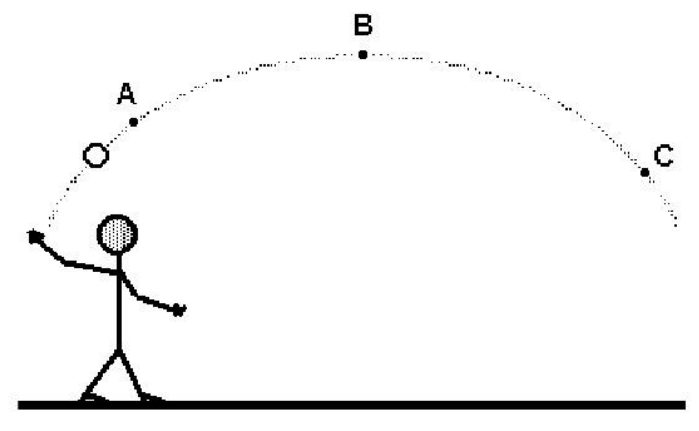

As setas nos esquemas seguintes simbolizam as forças exercidas sobre a pedra.

17) No ponto $A$, qual é o esquema que melhor representa a(s) força(s) sobre a pedra?

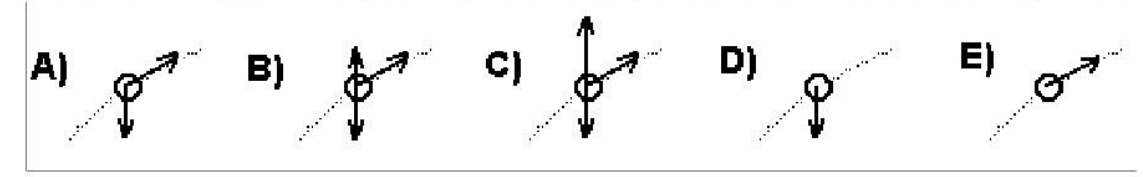

18) No ponto $B$, qual é o esquema que melhor representa a(s) força(s) sobre a pedra?
A) $\cdots \cdots$
B) $\stackrel{i g u a i s}{ } \rightarrow$
c)
D)
E)

19) No ponto $C$, qual é o esquema que melhor representa a(s) força(s) sobre a pedra?

A)

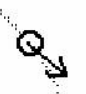

B)

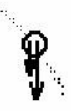

c)

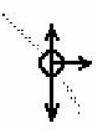

D)<smiles>[C+]1C2ON12</smiles>

E)

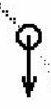

